\title{
Total Quality Management Usage for Quality Measurement in a Tertiary Institution -Accra Technical University
}

\author{
Roseline Mercy Abotsi* Linda Adzo Elorm Tormeti \\ Accra Technical University P.O. Box GP 561, Accra Ghana
}

\begin{abstract}
Quality measurement in examination processes is key to every educational set up. Therefore the need to develop a model for measuring quality in the application of Total Quality Management (TQM) to examination systems using Accra Technical University formally (Accra Polytechnic) in Ghana become relevant. In order to develop a model, a structured questionnaire was administered to 100 members of staff using purposive sampling technique to study the examination system and assess the performance of TQM principles as well as four Quality indicators - Timeliness, Integrity, Predictability and Satisfaction. Data obtained were analysed using Excel application and incorporated into the TQM model to determine the average scores for the TQM principles and Quality indicators. The TQM model developed tested the effects of TQM implementation on the quality of examinations. Results obtained indicate that staff are generally not satisfied with the quality of the examination processes. This implies that the model proves a good quality measurement instrument for the assessment of examination processes.
\end{abstract}

Keywords: Total Quality Management (TQM), Examinations, TQM Principles, Quality Parameters

DOI: $10.7176 / \mathrm{EJBM} / 13-10-11$

Publication date:May $31^{\text {st }} 2021$

\section{Introduction}

The Examination process serves as the Quality control in any educational institute. Students are trained by Teaching and learning processes by faculties and they are evaluated by the Examination process. Students meeting the set criteria are promoted to the next level or class and provided with a Certificate.

\subsection{Statement of the Problem (Aim of Study)}

Examinations are a core function of educational institutions and Quality is considered to be very important in Examinations. The Examination process measures the level of knowledge acquired by the students during the course of study. The examination process is the continuous evaluation of student's performance throughout the academic session.

According to Smith (1994) process improvement is the backbone of a successful TQM programme and must be clearly understood by all those involved.

The critical steps of process improvement are:

1. Create a flowchart of the process.

2. Measure performance

3. Collect and analyse the data.

4. Formulate the improvement proposal.

In a previous research, Abotsi and Tormeti, (2013), developed flowcharts of the examination process and assessed the performance of TQM principles in the examinations processes at Accra Technical University. Abotsi and Tormeti, (2013) evaluated TQM practices in the various processes by comparing quality practices in the examination system to nine TQM principles in literature. These TQM principles were Leadership Commitment, Policy and Plan Statement, Evaluation, Process Control and Improvement, Quality System Improvement, Participation of Staff, Recognition and Reward, Education and Training, Customer Focus, and Benchmarking.

The results showed that the examination system of Accra Technical University consisted of three stages: before Examinations, during Examinations and after examinations. TQM principles were not well developed for all three stages.

In order to improve the examination system of the institution it was necessary to obtain a tool for collecting quantitative data on TQM in examinations for analysis to aid in the implementation of TQM in the examination processes of Accra Technical University.

How can appropriate TQM measurements be developed to measure quality in the application of TQM to examinations systems?

Saunders and Graham (1992) developed a method for collecting quantitative data for TQM in the hotel industry. The method comprised a TQM measuring model and questionnaire for collecting information from customers. The information from the questionnaire was converted into quantitative data which was then incorporated into the TQM model and analysed.

In this study Saunders and Graham's (1992) TQM technique for the hospitality industry was adapted and modified to obtain a TQM model for examinations based on the TQM Framework and Principles, as well as on 
the quality dimensions of service.

The aim of this study was to use the TQM model for examinations to obtain quantitative data, and to analyse the data to determine the effects of TQM implementation on the quality of examinations in Accra Technical University.

\subsection{Literature Review}

Total Quality Management is a systematic way of guaranteeing that all activities within an organisation happen the way they have been planned. It is a management discipline concerned with preventing problems from occurring by creating the attitude and controls that make prevention possible. It is also about efficiency, productivity and long-term success.

According to various researches some principles and practices have to be adopted for a company to implement Total Quality Management effectively. According to Dean and Bowen (1994), TQM approach to management can be characterised by its principles. They further indicated that TQM implementation can only be accomplished through a set of principles. To improve performance, people need to know what to do, how to do it, have the right tools to do it and to be able to measure performance and received feedback on levels of achievement. Kanji (1995) intimated that TQM provides this by adhering to a set of principles. Some principles of TQM may differ among firms and industries, but there is unanimous agreement as to the importance of leadership by top management in implementing TQM. Such leadership is a pre-requisite to all strategy and action plans, according to Juran (1989) it cannot be delegated. Those firms that have succeeded in making total quality work for them have been able to do so because of strong leadership (Juran 1989). According to Ross (1993) TQM is the application of quality principles for the integration of all functions and processes within an organisation. Twelve principles of TQM indicated by Saraph, Benson, Schroeder (1989); Flynn, Schroeder and Sakakibara (1994); Ahire, Waller, and Golhar (1996) were selected for study and these are Leadership, Policy and Plan Statement, Evaluation, Process Control and Improvement, Quality System Improvement, Employee Participation, Recognition and Reward, Education and Training, Customer Focus, Supplier Quality Management, Product Design, and Benchmarking.

The components of perceived service quality are Reliability, Assurance, Responsiveness, and Empathy. These are external measures: they can be obtained only after the service is delivered. They thus suffer from appropriate service quality measures: a failure can be detected only when it is too late to respond and are of little use in monitoring and improving quality (Parasuraman, Zeikthaml \& Berry 1985).

We need internal measures which would help deliver the customers' expectations. Internal quality measures are able to indicate before delivery that the service will exceed the customer's expectations.

The four internal quality standards for services as identified by Zimmerman and Enell (1988) are Timeliness, Integrity, Predictability, and Satisfaction (as sited by Saunders \& Graham, 1992).

Timeliness of service has been referred to by a number of authors as an important component in the quality of a service. It is a reasonable feature of service to be given high priority because the service has to be produced on demand and the interval in provision is an element of the actual product.

Timeliness may be separated into three types: access time (the time taken to gain attention from the company); queuing time (this can be influenced by the length of the queue, or its integrity); and action time (the time taken to provide the required service).

Integrity deals with the completeness of service and must set out what elements are to be included in the service in order for the customer to regard it as a satisfactory product. This standard will set out precisely what features are essential to the service.

Predictability refers to the consistency of the service and also the persistence, or the frequency of the demand. "Standards for predictability identify the proper processes and procedures that need to be followed and may include standards for availability of people, materials and equipment, and schedules of operation" (Zimmerman \& Enell, 1988) (as cited by Saunders and Graham, 1992).

Finally customer satisfaction is designed to provide the targets of success, which may be based on relative market position for the provision of a specific service. These are the external measures noted above.

Once these internal service standards are determined the next step is to develop measurement techniques to monitor how well the standards are being achieved.

According to Smith (1994) the process improvement process is the backbone of a successful TQM programme and must be clearly understood by all those involved. He proposed the following steps for process improvement

The critical steps of process improvement

1. Create a flowchart of the process.

2. Measure performance

3. Collect and analyse the data.

4. Formulate the improvement proposal and

5. Implement the improvement proposal. These will be addressed in the subsequent article 
The previous research by Abotsi and Tormeti, (2013) focused on understanding the existing examinations process of Accra Polytechnic by way of flowcharts and level of TQM practices. The study showed that the examination system of Accra Polytechnic consisted of three stages: before examinations, during examinations and after examinations and that TQM principles were not well developed for all three stages

Data must be collected and analysed in order to determine potential improvements to the examinations process

This study focused on the development of a tool for collecting quantitative data on TQM in examinations, collection of data with the tool, analyses of the data and the formulation of proposals for improving the examination system of the University.

\subsection{Methodology}

In this study a TQM model for the examination process was developed by using the four quality standards for services identified by Zimmerman and Enell (1988) and adopted by Saunders and Graham (1992) for Total Quality Management in the Hospitality Industry. These standards are timeliness, integrity, predictability, and satisfaction. Saunders and Graham (1992) developed a method for collecting quantitative data for TQM in the hotel industry. The method comprised a TQM measuring model and questionnaire for collecting information from customers. The information from the questionnaire was converted into quantitative data which was then incorporated into the TQM model.

Saunders and Graham's (1992) TQM technique for the hospitality industry was adapted and modified to obtain a TQM model for examinations.

The implementation of the TQM model for examinations was demonstrated by using the model as a guide for the development of interview and survey questionnaires for collecting quantitative data based on the TQM Framework and Principles as well as on the Quality dimensions of service. A Cross-Sectional Study approach was used which involved a one-time survey of a sample of employees of Accra Technical University. Information was obtained by questionnaires and interviews. Questionnaires were distributed by hand to a sample of 100 staff of Accra Technical University. The quantitative data obtained was then incorporated into the TQM model.

A qualitative descriptive approach was then used to examine the relationship between implementation of TQM principles and customer oriented quality parameters of timeliness, integrity, predictability, and satisfaction.

\subsection{Results and Discussions}

The model developed for measuring implementation of TQM principles in the examination system of Accra Technical University (Table 1) as well as measuring the customer related quality parameters of timeliness, integrity, predictability, and satisfaction (Figure 1) was used to collect data from the respondents.

\begin{tabular}{|l|l|l|}
\hline S/NO & TOTAL QUALITY MGT PRINCIPLES & RESPONSES \\
\hline 1. & Leadership Commitment & 3.09 \\
\hline 2. & Policy and Plan Statement & 2.92 \\
\hline 3. & Evaluation & 2.77 \\
\hline 4. & Process Control and Improvement & 3.06 \\
\hline 5 & Quality System Improvement & 2.97 \\
\hline $6 .$. & Participating of Staff & 2.96 \\
\hline 7. & Recognition and Reward & 2.41 \\
\hline 8. & Education and Training & 2.45 \\
\hline 9. & Customer Focus & 2.46 \\
\hline 10. & Benchmarking & 2.47 \\
\hline
\end{tabular}

Table 1: Implementation of Total Quality Management Principles in the examination system of Accra Technical University - (Mean Responses based on a scale of 1-5 Likert scale)

From the scoring scale provided, any mean score equal to or greater than 3.50 could be regarded as being implemented in the management of examinations at Accra Technical University.

Respondents could not agree whether Management actively participates in quality management activities relating to examinations and also that management discusses quality issues related to examination during top management meetings.

Respondents were also not sure whether the University has clearly spelt out quality Improvement plans on issues relating to examinations. There is also no consensus whether Lecturers and Examination Officers are involved in making policies and plans relating to examinations or not.

There is also no consensus whether the University regularly conducts quality assessment on procedures, activities and issues relating to examinations. Staff members are not actively involved in quality-related activities relating to examination issues in the University. Members of staff assigned to handle examination issues are also not very much committed to the success of the examination process. It is probable that staff do not see the importance of quality principles because they do not participate in quality management activities. They are 
therefore not motivated to implement quality management (Juran and Gryna, 1993). Feigenbaum (1991) stated that to have effective employee participation, employee contributions and ideas must receive serious consideration and be placed into operation whenever the recommendations are sound and relevant.

The University does not recognise and reward employee's efforts in improving the quality of the examination system. The University collects extensive complaint information from students on issues relating to examinations and these complaints are not treated with top priority. The University does not conducts a customer (student) satisfaction survey every year. A successful firm recognises the need to put the customer first in every decision made (Philips Quality, 1995). The key to quality management is maintaining a close relationship with the customer in order to fully determine the customer's needs, as well as to receive feedback on the extent to which those needs are being met. To improve customer focus efforts, customer complaints should therefore be treated with top priority.

The Accra Technical University does not do effective benchmarking of its examination system to those of well-established tertiary institutions.

Table 2. TQM Principles in decreasing order of implementation in the Examination System of Accra Technical University

\begin{tabular}{lll}
\hline & Quality Principles & Mean score \\
\hline 1 & Process Control and Improvement & 3.20 \\
2 & Leadership Commitment & 3.10 \\
3 & Quality System Improvement & 2.97 \\
4 & Participation of Staff & 2.96 \\
5 & Policy and Plan Statement & 2.92 \\
6 & Evaluation & 2.77 \\
7 & Customer Focus & 2.46 \\
8 & Benchmarking & 2.45 \\
9 & Education and Training & 2.45 \\
10 & Recognition and Reward & 2.41 \\
\hline
\end{tabular}

The institution spends the most effort on Process Control and Improvement (Table 2) and the least effort on recognising and rewarding deserving staff. Focusing on the customer is ranked seventh in the order of importance of implementation of TQM principles in the examination system. This relative lack of concern for the customer is not good for a service organisation because the customer is supposed to be "number one" for any service organisation

The mean figures of the TQM factors ranges from 2.41 to 3.20, and this shows that generally the respondents view the quality system for examinations to be generally weak. The results indicate the difficulties faced by the University in implementing TQM for examinations.

Many empirical studies have found that top management support for quality was a key factor in quality improvement. Ahire and O'Shaughnessy (1998) asserted that companies with high top management commitment have the ability to come out with high quality output in contrast with those with low top management support. A study conducted by Garvin (1986), suggested that high levels of quality performance were always accompanied by an organisational commitment to quality goal; high product quality or high performance did not exist without strong top management commitment. Randell and Mannas (1999) also intimated that strong, positive, open-minded leadership will give rise to long-term and sustainable business success.

The respondents were not satisfied with the regularity of quality assessment, and this was reflected in the 2.77 mean score. The School Boards are supposed to sit and discuss examination results and do any necessary corrections before submitting the results to the Academic Board for consideration. The fact that the results released by the Academic Board sometimes contain errors suggests that members of School Boards and Academic Board are not adequately equipped for the task. In 12 of the 13 departments the student population ranges from 200 to about 1200. At the school boards the numbers range from 1,500-5,500, and at academic board the student population under consideration is greater than 9,000. Detecting errors in the results of all the students would be easier to do at the departmental level, but once this is not achieved it becomes more difficult to do so at the School Board and academic Board because of the increasing population under consideration.

Staff education is not effective. According to Burrill and Ledolter, (1999), people are the only real source of a company's competitive advantage. Quality awareness education should be considered to ensure process quality, and customer satisfaction. Different types of training should be offered to meet employees' specific needs. Education and training should aim at equipping every member of staff working in examination related activities with the requisite knowledge in quality management and improvement so that they can perform their jobs effectively. Education and training can improve staff members' knowledge and skills which will in turn influence their development. This would enhance the capacities of employees to generate innovative ideas for solving operational problems. Training provides an opportunity for communication of new organisational strategy, values, and ways of performing tasks. According to Deming, (1986) Employees' commitment and satisfaction may be 
enhanced through training leading to efficiency and effectiveness.

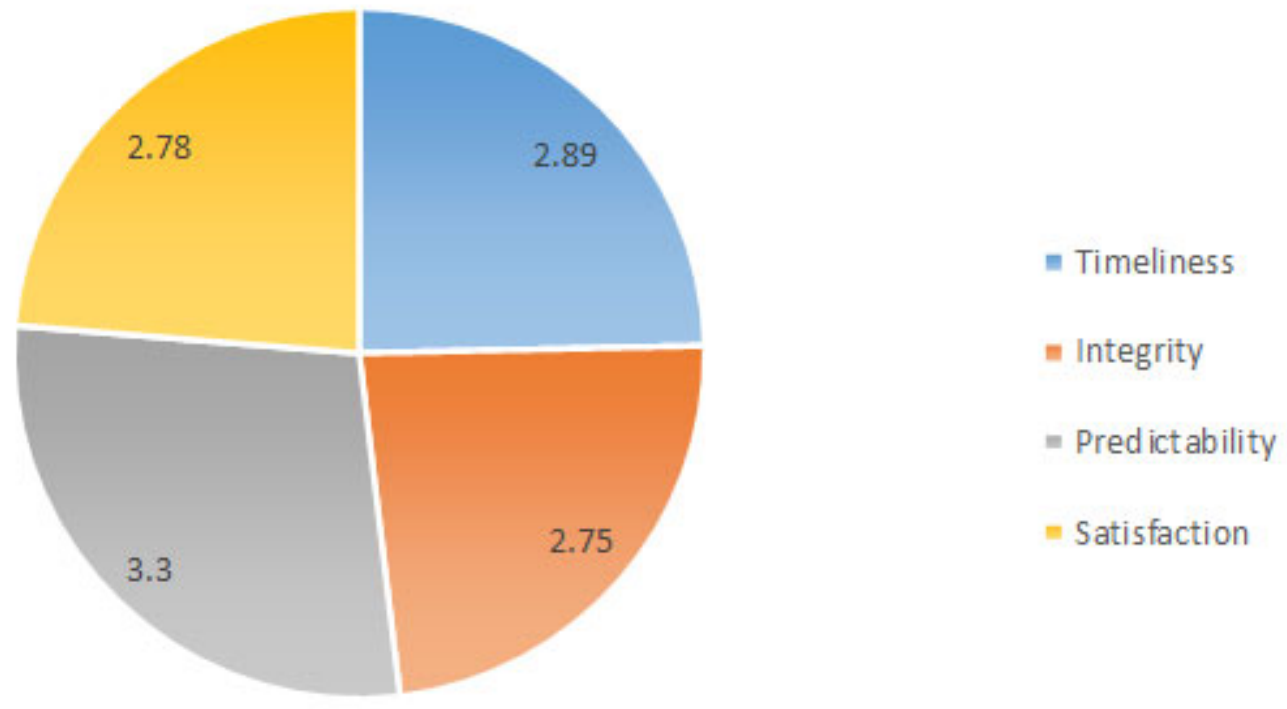

Figure 1: Quality Parameters in the examination system of Accra Technical University - (Mean Responses based on a scale of 1-5 Likert scale)

The 2.89 mean score (Figure 1) indicates that in general, lecturers do not collect their scripts for marking on time, and also do not submit their marks on time and this would in turn delay the compilation of the results. There is a poor compliance to the submission of questions by the sixth week of the semester, and also to the submission of examination marks by the lecturers to the departments (Figure 1). Student's complaints are also not responded to quickly. The element of timeliness is therefore poor in the examination process.

Examinations fairly proceeds according to the schedule on the examination timetable. However, examination information provided is not always accurate. Documentation of examination information is also not adequate. The integrity (Figure 1) of the examinations is therefore low as indicated by 2.75 .

The conduct of examinations is not predictable. Lecturers do not always submit questions on time to the departments. On the day of examinations, the Examinations Office does not always release the printed questions on time to the various centres' to be distributed to the invigilators. Lecturers also fail to always submit marks to the departments on time for the compilation of the student's results. The compiled results are therefore not released on time which should be at most six weeks after examinations for continuing students and at most six months after the final year students.

The overall mean score of 2.78 (Figure 1) from the respondents who are staff of the University indicates that in general they are not satisfied with the quality of examination processes.

\subsection{Conclusions and Recommendations}

This section presents the summary of findings, recommendations, directions for future research and concluding remarks.

The main aim of the project was to develop a model for measuring quality in the application of TQM to the examination system of Accra Technical University.

This was done by:

a. Creating a flowchart of the examination process of Accra Technical University by studying the examination system to find out the various processes involved.

b. Obtaining a TQM measuring model and questionnaire for collecting information.

c. Assessing the performance of TQM practices involved in the examinations processes at Accra Polytechnic.

The TQM practices in the various processes were identified by comparing quality practices in the examination system to TQM principles in literature.

In developing a TQM model for the examination process, the four quality standards for services as identified by Zimmerman and Enell (1988) and adopted by Saunders and Graham (1992) for Total Quality Management in The Hospitality Industry were used. The model for examinations was obtained through the further development and adaptation of Saunders and Graham (1992) technique for obtaining quantitative data for Total Quality Management in the hospitality industry.

The application of the TQM model was demonstrated by using the TQM model as a guide for the development 
of interview and survey questionnaires for collecting quantitative data based on the TQM Framework and Principles as well as the Quality dimensions of the examination processes. The quantitative data obtained from the questionnaire was incorporated into the TQM model.

A qualitative descriptive research was used to examine the relationship between the implementation of TQM principles and some customer oriented quality parameters (timeliness, integrity, predictability, and satisfaction).

A Cross-Sectional Study approach was used which involved a one-time survey of a sample of employees of Accra Technical University.

Information was obtained by questionnaires and interviews. Questionnaires were distributed by hand to a sample of 100 staff of Accra Technical University.

Some of the TQM principles which were considered were Leadership Commitment, Policy and Plan Statement, Evaluation, Process Control and Improvement, Quality System Improvement, Participation of Staff, Recognition and Reward, Education and Training, Customer Focus, and Benchmarking. TQM principles are not well developed for the examination system of Accra Technical University.

A number of conclusions have been obtained from this research. First, a total quality management model related to the Accra technical Examination System has been developed.

Secondly, the instruments for measuring TQM implementation and overall management of examinations in Accra Technical University are valid, and can be used by other researchers to test the effects of TQM implementation on the quality of examinations.

Thirdly, the case study reveals that the TQM implementation model developed in this study is applicable in practice. This model can be used by tertiary institutions to improve their TQM implementation efforts for examinations. The case study further shows that this TQM implementation model can be used by organisations to self-assess the quality improvement efforts in examination systems and measure their progress over time. This model can help identify quickly which areas of examination management urgently need improvement thereby allowing resources to be allocated more wisely and more effectively.

This model shows that the application of TQM practices can lead to overall improvements in the management of examinations in Accra Technical University.

Further research should obtain information from the students to know their perceptions of the quality of the examination processes. Further research should also aim at formulating an improvement proposal for the various processes.

TQM should be implemented to improve the quality of the examination system in Accra Technical University. The TQM model developed should be applied in the management of examinations in Accra Technical University.

A root cause, analysis should be used to determine the root causes of the problems occurring in the process. This analysis would help in making the improvement proposal to treat the "disease" rather than the symptom (Smith 1992).

\section{References}

Abotsi R. M. \& Tormeti L. A. E. 2013, Evaluating the Accra Polytechnic Examination System for Total Quality Management Principles, European Journal of Business and Management Vol.5, No.31, 2013

Ahire, S., \& O'Shaughnessy, K. (1998). The role of top management commitment in quality management: An empirical analysis of the auto parts industry. International Journal of Quality Science, 3(1), 5-37.

Ahire, S.L., Waller, M.A., \& Golhar, D.Y. (1996), Development and validation of TQM implementation constructs. Decision Sciences, 27 (1), 23-56.

Burrill, C.W., \& Ledolter, J. (1999). Achieving quality through continual improvement, New York, NY: John Wiley \& Sons.

Deming, W.E. (1986). Out of crisis. Massachusetts Institute of Technology, Center for Advanced Engineering Study, Cambridge, MA. Feigenbaum, A.V. (1991). Total quality control, (3 ${ }^{\text {rd }}$ ed). New York, NY: McGrawHill.

Flynn, B.B., Schroeder, R.G. \& Sakakibara, S. (1994). A framework for quality management research and an associated measurement instrument. Journal of Operations Management, 11, 339-366.

Garvin, D.A. (1986). Quality problems, policies and attitudes in the United States and Japan: An exploratory study. Academy of Management Journal, 29, 653-673.

Juran, J. M. (1989). Juran on leadership for quality: An executive handbook. New York, London: Free Press, Collier Macmillan

Juran, J.M., \& Gryna, F.M. (1993). Quality planning and analysis ( $3^{\text {rd }}$ ed.).New York, NY: McGraw-Hill.

Kanji, G. K. (1995). Total quality management proceedings of the first world congress. UK, London: Champman and Hall.

Parasuraman, A., Zeikthaml, V.A., \& Berry, L.L. (1985). A conceptual model of service quality and its implications for future research. Journal of Marketing, 49, 41-50.

Philips Quality. (1995). Philips Quality - Let's make things better. Eindhoven, Netherlands: Corporate Quality 
Bureau, Philips Electronics

Randell, M., \& Mannas, P. (1999). Leadership and organisational development, In S.K.M. Ho (Ed.), TQM and Innovation (pp. 506-511). School of Business, Hongkong Baptist University, Hongkong.

Ross, J.E. (1993). Total quality management. Delray Beach, FL: St. Lucie Press,

Saraph, J.V., Benson, G.P., \& Schroeder, R.G. (1989). An instrument for measuring the critical factors of quality management. Decision Sciences, 20, 810-829.

Saunders, I. W., \& Graham, M. A. (1992). Total quality management in the hospitality industry, Queensland, Australia: Bond University, 3, 5-17

Smith, A . W. (1994). TQM success - or, it's the process, stupid. Journal of Property Management. Retrieved from http://www.allbusiness.com/management/benchmarking-quality-improvement/473431-1.html.

Zhang, Z.H. (2000). Developing a model of quality management methods and evaluating their effects on business performance. Total Quality Management, 11 (1), 129-13 